\title{
Prevalence of impacted and transmigrated canine teeth in a Cypriote orthodontic population in the Northern Cyprus area
}

Beste Kamiloglu ${ }^{1 * \dagger}$ and Umay Kelahmet ${ }^{2+}$

\begin{abstract}
Background: The aim of this study was two-fold; (1) to evaluate the prevalence and patterns of impacted canines and transmigrated canine teeth, and (2) to evaluate the possible relationships between impacted teeth, malocclusions and systemic conditions in an orthodontic patient population.

Methods: The clinical records and panoramic radiographs of 453 patients [201 (44.3\%) male and 252 (55.7\%) female] referred to our outpatient clinic between January 2008 and January 2012 were retrospectively evaluated. The number, position, localization (right/left) and transmigration of teeth, as well as sex, age and systemic conditions of patients, were noted. An impacted canine was considered to be transmigrated when at least part of its length had crossed the midline. Complications related to impacted teeth (pain, cystic changes, root resorption or eruption disturbance of adjacent teeth) were also noted. A p-value less than 0.05 was considered statistically significant.

Results: Impacted and transmigrated canine teeth were found in 16 (3.53\%) and two (0.44\%) patients in the study group, respectively. Root resorption was seen in four teeth adjacent to impacted canines. No statistical difference was found among gender, location, malocclusion and impaction of the teeth $(p>0.05)$. However, maxillary canine impaction occurred significantly more frequently than mandibular canine impaction $(p<0.05)$.

Conclusions: The early detection of impacted as well as transmigrated teeth is crucial for successful treatment, therefore demographic studies are important. Although larger samples are required, this study provides a baseline regarding the frequency and type of impacted canines in this particular population.
\end{abstract}

Keywords: Impacted teeth, Radiographic evaluation, Transmigration, Premolars, Canine, Retrospective evaluation

\section{Background}

Dental anomalies involving alterations in number, size and structure of teeth often present a major challenge for dental practitioners [1]. Undiagnosed and untreated, many of these dental anomalies may ultimately present complex treatment challenges in the areas of endodontics, orthodontics, prosthodontics and restorative dentistry [1]. From a therapeutic point of view, through early recognition of dental anomalies, many complications can be avoided [2,3]. Baccetti [4] reviewed the literature published before 1963, and reported that there is a possibility that tooth number polymorphism in man is not an isolated

\footnotetext{
* Correspondence: 59beste@gmail.com

${ }^{\dagger}$ Equal contributors

${ }^{1}$ Consultant Orthodontist DDS PhD, Department of Orthodontics, Faculty of Dentistry, Near East University, Mersin 10, Turkey

Full list of author information is available at the end of the article
}

phenomenon, but bears a fundamental relationship to the size, development and calcification timing of the dentition as a whole. The spectrum of possible associations among tooth anomalies includes multiple missing teeth, impacted teeth, aplasia of upper lateral incisors and intraosseous displacement of maxillary canines [4].

Tooth impaction is a common dental condition frequently reported in the literature [5-8]. It was stated that when a tooth is unerupted more than 1 year after the normal age for eruption, it is then defined as "impacted" [9]. The prevalence of impacted teeth varies according to the population, and is reported to be between 6.9 and $76.6 \%$ [5-10]. The most commonly impacted teeth were reported as third molars, maxillary canines, maxillary central incisors and premolars. These variable rates may 
have occurred using different age groups, sample sizes and selection of patients [11-14].

Canine impaction is relatively common and has been reported extensively in different populations in the literature, ranging from $0.8-3.6 \%$ of the general population [15-19]. Transmigration, which is defined as migration of an impacted tooth across the midline, is a rarer condition than standard impaction cases [20]. The prevalence of transmigration in different populations and ethnic groups was the subject of several studies, and was reported to be between 0.1 and $0.34 \%[19,21]$. Accordingly, genetic alterations and ethnic differences were reported to be the key factors for the occurrence of dental alterations [22]. Traits that may occur more commonly in certain ethnic groups may be considered to be specific to that population [3].

Although most impacted teeth are asymptomatic, some can cause complications such as pain, infection cysts, tumors, resorption of the adjacent teeth, jaw fractures, malpositioning of the mandibular anterior teeth and marginal bone resorption near the adjacent teeth $[5,23]$.

The aim of this study was to evaluate the prevalence and patterns of impacted canines and transmigrated canine teeth and investigate the associated pathologies and evaluate possible relationships between impacted teeth, malocclusions and systemic conditions in an orthodontic patient population.

\section{Methods}

This was a population-based, retrospective, descriptive study based on the panoramic radiographs and clinical records of 453 patients [201 (44.3\%) male and 252 (55.7\%) female] ranging in age from 14 to 20 years, who attended our outpatient orthodontic clinic for evaluation of malocclusions from January 2008 to January 2012. The study was approved by the Institutional Review Board. Also, prior to taking any radiographs or performing intra/extraoral examination, patients gave their informed consent according to the principles of the Helsinki Declaration, including all amendments and revisions. Collected data were only accessible to the researchers. Moreover, all examiners in the study only examined the radiographs and were blinded to any other patient data in the radiographic examination procedure.
The included sample consisted of 453 panoramic radiographs together with the subjects' patient records. Digital panoramic radiographs were taken with a Planmeca PM 2002 cc Proline (Helsinki, Finland) set at 1.25 magnification as recommended by the manufacturer, with a maximum sensor resolution of 9 line pairs $/ \mathrm{mm}$. All radiographs were acquired with a standardized head position, stabilized by head rods. The exposure settings were dependent on the patient, set from $60-66 \mathrm{kVp}, 4-8 \mathrm{~mA}$ for $18 \mathrm{~s}$ for each exposure, with a half-value layer of $2.47 \mathrm{~mm}$ of aluminum. All digital images were stored in a computer database using the manufacturer's software (Dimaxis Pro, version 4.0.5, Planmeca). Each image was magnified to $110 \%$ and contrast and brightness were optimized to produce the best image for viewing under standardized conditions. All reviewing processes were performed on a 17-inch flat panel color active matrix TFT medical display (Samsung SyncMaster 920 N, South Korea) with a resolution of $1280 \times 1024$.

It has been suggested that the following clinical signs might be indicative of canine impaction $[24,25]$ :

1. Delayed eruption of the permanent canine or prolonged retention of the deciduous canine beyond 14-15 years of age,

2. Absence of a normal labial canine bulge,

3. Presence of a palatal bulge, and

4. Delayed eruption, distal tipping or migration (splaying) of the lateral incisor.

An impacted canine was considered transmigrated when at least part of its length had crossed the midline [17,21]. The numbers, positions and locations (right/left) of impacted/transmigrated canine teeth, as well as patient sex, age, retained deciduous canines and any other associated pathologies, were noted after retrospective evaluation of the patients' general histories, clinical and radiographic records.

The position of maxillary and mandibular impacted canine teeth were classified according to Mupparapu's classification [26] as:

1. Type 1: Canine positioned mesio-angularly across the midline within the jaw bone, labial or lingual to

Table 1 The distribution of canine impaction and transmigration according to location and gender

\begin{tabular}{|c|c|c|c|c|c|c|c|}
\hline Impaction & Patients & $\%$ in sub-groups & $P$ value & Males (n) & $P$ value & Females $(n)$ & P-value \\
\hline Canine Impaction & $16 / 453$ & 8.16 & & 7 & & 9 & \\
\hline Maxillary Canine & $12 / 453$ & 75 & $<0.05$ & 4 & $>0.05$ & 6 & $>0.05$ \\
\hline Mandibular Canine & $4 / 453$ & 25 & & 3 & & 3 & \\
\hline Canine Transmigration & $2 / 453$ & 0.44 & & 1 & & 1 & \\
\hline Maxillary Transmigration & $2 / 2$ & 100 & $>0.05$ & 1 & $>0.05$ & 1 & $>0.05$ \\
\hline Mandibular Transmigration & $0 / 2$ & 0 & & 0 & & 0 & \\
\hline
\end{tabular}

$P$ value less than 0.05 indicates significance. 
anterior teeth, and the crown portion of the tooth crossing the midline.

2. Type 2: Canine horizontally impacted near the inferior border of the mandible below the apices of the incisors.

3. Type 3: Canine erupting either mesial or distal to the opposite canine.

4. Type 4: Canine horizontally impacted near the inferior border of the mandible below the apices of either premolars or molars on the opposite side.

5. Type 5: Canine positioned vertically in the midline (the long axis of the tooth crossing the midline) irrespective of eruption status.

Two orthodontic consultants evaluated the images independently prior to the investigation. Calibration of the examiners was undertaken until intra-examiner reliability and reproducibility was achieved. Kappa statistics was used for assessing the agreement between observers using the NCSS 2007 statistical software (NCSS and GESS, NCSS, LLC, Kaysville, UT, USA). Inter-examiner discrepancies were solved by consensus and agreement [27]. To assess reliability, all radiographs were reexamined 2 months after the initial examination by these two observers for the reliability of the results. Pearson's chi-squared test, Fisher's exact test and Student's t-test were performed for statistical analysis of differences in age, gender, localization and measurements $(\mathrm{p}<0.05)$.

\section{Results}

Repeated evaluations showed no significant inter- and intra-observer difference $(p>0.05)$. There were no discordances in detecting the impacted and transmigrated canines between the two reviews. The kappa values for intra-observer as well as inter-observer detection of impacted and transmigrated canine were 1.0. All observers identified the same number and cases of canine impaction and transmigration in this study.

The distributions of impacted and transmigrated canines according to location and gender are shown in Table 1. Sixteen out of 453 (3.53\%) patients had impacted canines (with a total of 18 teeth affected). Of all patients, seven (43.75\%) were male and nine $(56.25 \%)$ were female. Impacted canines were in the maxilla in 12 (75\%) patients, while four (25\%) patients showed mandibular canine impaction. In terms of impacted canine teeth according to gender, males had $1.99 \%$ in the mandible and $6.96 \%$ in the maxilla $(\mathrm{p}<0.05)$, while the females' corresponding values were $1.01 \%$ and $3.52 \%(\mathrm{p}<0.05)$.

There were five right and seven left impacted maxillary canines, while there were two right and two left mandibular impacted canine teeth. Of all patients, two impacted canines were bilateral (Figure 1), whereas 14 were unilaterally impacted teeth (Figure 2). No significant difference

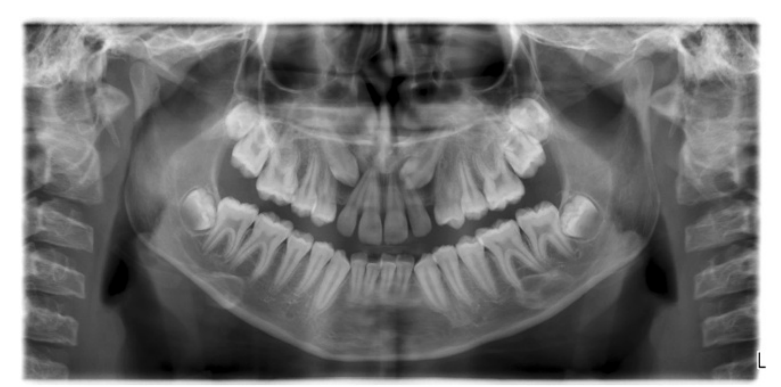

Figure 1 Panoramic image showing bilateral impacted canine in a female patient.

was found according to gender for impacted canine teeth $(\mathrm{p}>0.05)$ (Table 2).

For all impacted canines, Type 1 position was the most common. There were no statically significant differences according to gender $(p>0.05)$. However, we found significant differences for location ( $p>0.05)$, with maxillary canine impaction significantly more frequent than mandibular canine impaction (Table 3).

In all patients, only two $(0.44 \%)$ transmigrated maxillary canine teeth were found (Figure 3) (Types 1 and 2). No statistically significant difference was found according to gender $(p>0.05)$. However, these two transmigrated teeth were impacted in the maxilla (Table 3). Associated pathologies were also investigated in this study. Root resorption was seen in four teeth adjacent to impacted canines, all located in the maxilla.

\section{Discussion}

Knowledge of dental anomalies in patients is fundamental for treatment planning [28]. Different prevalence was reported among different ethnic groups [2]. Ethnic background of the sample may result in higher or lower rates of some anomalies [4]. Traits that may occur more commonly in certain ethnic groups may be considered specific to that population [3]. According to Stecker et al. [1], dental practitioners who are aware of ethnic differences in the occurrence of dental anomalies will be more

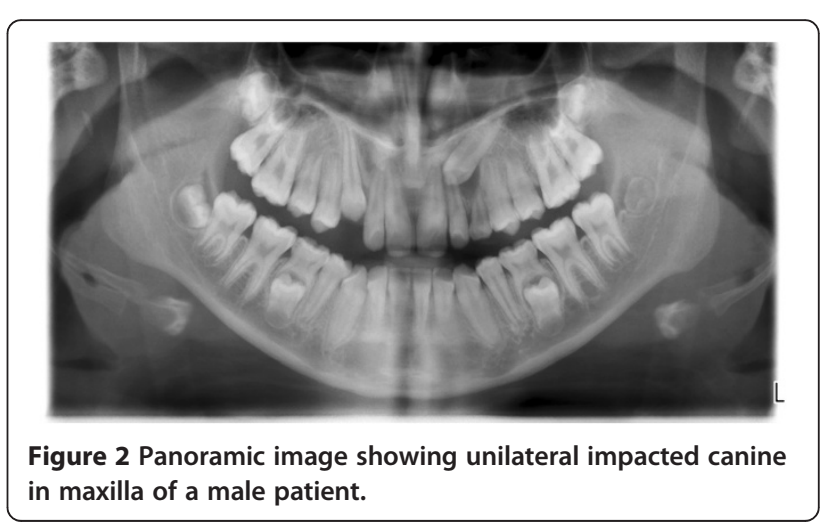


Table 2 The distribution of number and genders of patients associated with canine impaction

\begin{tabular}{lllll}
\hline Gender & \multicolumn{3}{c}{ Number of impacted canines } & P-value \\
\cline { 2 - 4 } & Unilateral $\mathbf{n}(\%)$ & Bilateral $\mathbf{n}(\%)$ & Total $\mathbf{n}(\%)$ & \\
\hline Female & $8(88.8)$ & $1(11.9)$ & $9(100.0)$ & $>\mathbf{0 . 0 5}$ \\
Male & $6(88.8)$ & $1(11.9)$ & $7(100.0)$ & \\
Total & $14(87.5)$ & $52(12.5)$ & $16(100.0)$ & \\
\hline
\end{tabular}

$P$ value less than 0.05 indicates significance.

aware in finding them in patients during routine examinations, and may be predictive of normal patterns of tooth development and/or eruption, allowing for prompt clinical intervention to avoid complicating pathology.

Canine impaction is one of the anomalies that should be considered by clinicians in detail. There are various studies in the literature related to impacted and transmigrated teeth $[17,18,20,29-37]$, but only a few comprehensive studies are available. As found in previous reports, canine impaction is more prevalent in the maxilla than the mandible. According to the literature, the prevalence of maxillary canine impaction ranges between 0.8 and $2.8 \%$ among different populations. Mandibular canine impaction is relatively rare $[16,17,21,38]$.

Chu et al. [5] investigated the prevalence of impacted teeth and their orientations, but did not mention canine transmigration. Aktan et al. [21] reported canine transmigration together with other impacted teeth, but did not include their orientation. Meanwhile, in their report they excluded third molars similarly to Fardi et al. [38]. As found previously, in this study canine impaction was more prevalent in the maxilla than in the mandible (30 teeth in the maxilla versus seven teeth in the mandible).

In this study, transmigration was also evaluated and a prevalence of $0.44 \%$ (2/453) was found. Previous studies indicated a prevalence varying between 0.1 and $4.51 \%$. Shah et al. [10] found eight (0.1\%) transmigrated mandibular canines and $4.06 \%$ maxillary canine impaction in

Table 3 The classification of impacted and transmigrated canine teeth in the maxilla and mandible

\begin{tabular}{|c|c|c|c|c|}
\hline & \multicolumn{2}{|c|}{ Mandible } & \multicolumn{2}{|c|}{ Maxilla } \\
\hline & $\begin{array}{l}\text { Impacted } \\
\text { canine }\end{array}$ & Transmigration & $\begin{array}{l}\text { Impacted } \\
\text { canine }\end{array}$ & Transmigration \\
\hline Position & $\mathrm{n}(\mathrm{M} / \mathrm{F})$ & $\mathrm{n}(\mathrm{M} / \mathrm{F})$ & n (M/F) & $\mathrm{n}(\mathrm{M} / \mathrm{F})$ \\
\hline None & $200 / 251$ & - & 193 / 248 & - \\
\hline Type 1 & $1 / 0$ & - & $3 / 2$ & $1 / 0$ \\
\hline Type 2 & $0 / 1$ & - & $3 / 1$ & $0 / 1$ \\
\hline Type 3 & - & - & $1 / 0$ & - \\
\hline Type 4 & - & - & $0 / 1$ & - \\
\hline Type 5 & - & - & $1 / 0$ & - \\
\hline Total & 201 / 252 & - & 201 / 252 & $1 / 1$ \\
\hline
\end{tabular}

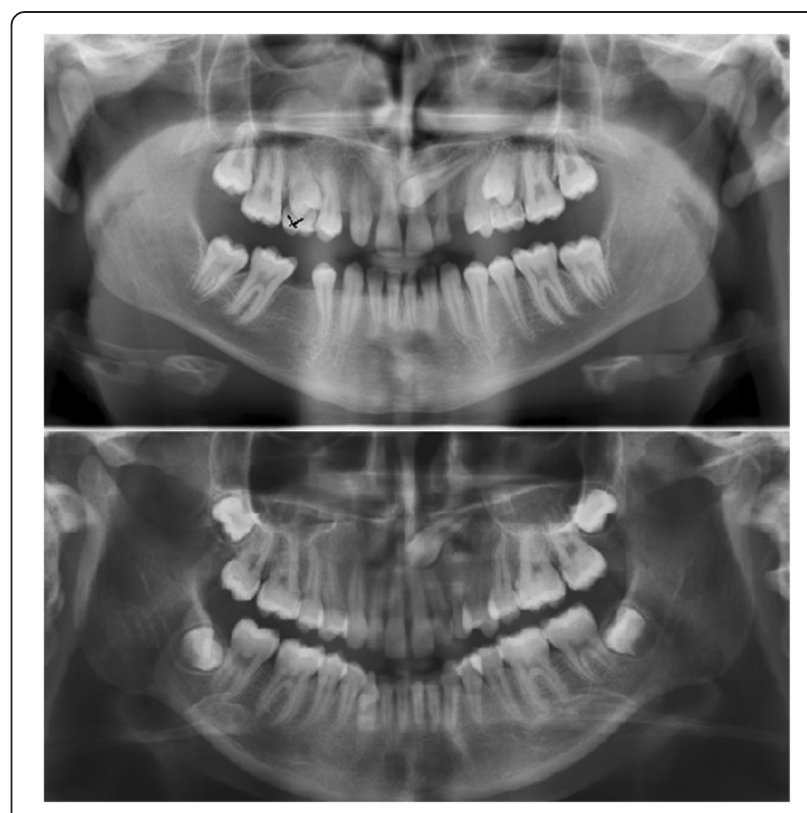

Figure 3 Panoramic images showing transmigrated canine teeth in maxilla.

7886 individuals. Aktan et al. [21] found a prevalence of $0.34 \%$ for transmigrated mandibular canines and $0.14 \%$ for maxillary transmigrated canines, while a recent study [37] found a $0.1 \%$ prevalence of transmigrated canines in 12,000 patients. However, studies like Zvolanek's [39] failed to find any cases in 4000 individuals. Our results were in line with previous studies.

Since almost all canine transmigrations are asymptomatic, they are usually diagnosed in routine radiographic assessments [17,20,26,31]. A small number of patients complain of pain, infection, swelling or cyst formation resulting from impacted and transmigrated canines. In this study, root resorption was seen in four teeth adjacent to impacted canines, all located in the maxilla. Bacetti [4] concluded in his review that the existence of associations between different dental anomalies is clinically relevant, as the early diagnosis of one anomaly may indicate an increased risk for others, and reported that the future analysis of a broader spectrum of dental and eruption anomalies in man may reveal further or different patterns or associations. In another study, Sørensen et al. [40] analyzed radiographic evidence of dental deviations with palatally or labially located ectopic canines. Authors of that study recommended that special attention should be given to dental deviations such as invaginations, crown and root deviations including taurodontic molar roots and agenesis as possible risk factors associated with ectopic eruption of maxillary canines, so early identification of patients at risk and appropriate interceptive treatment may reduce ectopic eruption of maxillary canines. 
Still, this study has limitations as the sample size was small and the sample population was only representative of the patient pool at the Faculty of Dentistry. Wider population groups should be studied in Cyprus. However, some authors still believe that the prevalence rates of canine impaction may reflect the prevalence rates of these anomalies in the general population.

\section{Conclusions}

The information given in this study could be added to information obtained from other studies on unerupted impacted and transmigrated canine teeth so that a useful clinical database on this particular population could be created to constitute proper plans for managing impacted canines.

\section{Competing interests}

The authors declare that they have no competing interests.

\section{Authors' contributions}

BK and UK participated in the retrospective evaluation of the data. BK prepared the manuscript. BK and UK are responsible for the literature search and wrote the paper. Both authors read and approved the final manuscript.

\section{Acknowledgments}

We thank the Oral \& Maxillofacial Radiology Department for providing us with the retrospective data and radiographs of the study sample.

\section{Author details}

${ }^{1}$ Consultant Orthodontist DDS PhD, Department of Orthodontics, Faculty of Dentistry, Near East University, Mersin 10, Turkey. ${ }^{2}$ Research Assistant DDS, Department of Orthodontics, Faculty of Dentistry, Near East University, Mersin 10, Turkey.

Received: 30 December 2013 Accepted: 29 May 2014 Published: 7 June 2014

\section{References}

1. Stecker SS, Beiraghi S, Hodges JS, Peterson VS, Myers SL: Prevalence of dental anomalies in a Southeast Asian population in the Minneapolis/ Saint Paul metropolitan area. Northwest Dent 2007, 86:25-28.

2. Ezoddini AF, Sheikhha MH, Ahmadi H: Prevalence of dental developmental anomalies: a radiographic study. Community Dent Health 2007, 24:140-144.

3. King NM, Tongkoom S, Itthagarun A, Wong HM, Lee CK: A catalogue of anomalies and traits of the primary dentition of southern Chinese. J Clin Pediatr Dent 2008, 32:139-146.

4. Baccetti T: A controlled study of associated dental anomalies. Angle Orthod 1998, 68:267-274.

5. Chu FCS, Li TKL, Lui VKB, Newsome PRH, Chow RLK, Cheung LK: Prevalence of impacted teeth and associated pathologies-a radiographic study of the Hong Kong Chinese population. Hong Kong Med J 2003, 9:158-163.

6. Hattab FN, Rawashdeh MA, Fahmy MS: Impaction status of third molars in Jordanian students. Oral Surg Oral Med Oral Pathol Oral Radiol Endod 1995, 79:24-29.

7. Peltola JS: A panoramatomographic study of the teeth and jaws of Finnish university students. Community Dent Oral Epidemiol 1993, 21:36-39.

8. Yamaoka M, Furusawa K, Yamamoto M: Influence of adjacent teeth on impacted third molars in the upper and lower jaws. Aust Dent $J 1995$, 40:233-235

9. Torres-Lagares D, Flores-Ruiz R, Infante-Cossio P, Garcia Calderon M, Gutierres Perez JL: Transmigration of impacted lower canine. Case report and review of the literature. Medicina Oral Patologia Oral Cirugia Bucal 2006, 11:171-174.
10. Shah RM, Boyd MA, Vakil TF: Studies of permanent tooth anomalies in 7886 Canadian individuals. I: impacted teeth. Dent J 1978, 44:262-264.

11. Murray P, Brown NL: The conservative approach to managing unerupted lower premolars two case reports. Int J Paediatr Dent 2003, 13:198-203.

12. Lee PP: Impacted premolars. Dent Update 2005, 32:152-154.

13. Karapanou V: Endodontic management of an impacted premolar. J Clin Pediatr Dent 2005, 29:293-298.

14. McNamara C, McNamara TG: Mandibular premolar impaction:2 case reports. J Can Dent Assoc 2005, 71:859-863.

15. Grover PS, Lorton $L$ : The incidence of unerupted permanenet teeth and related clinical cases. Oral Surg Oral Med Oral Pathol 1985, 59:420-425.

16. Aras MH, Büyükkurt MC, Yolcu U, Ertas U, Dayi E: Transmigrant maxillary canines. Oral Surg Oral Med Oral Pathol Oral Radiol Endod 2008, 105:e48-52.

17. Aydin $U$, Yilmaz H, Yildirim D: Incidence of canine impaction and transmigration in a patient population. Dentomaxillofac Radiol 2004, 33:164-169.

18. Mazinis E, Zafeiriadis A, Karathanasis A, Lambrianidis T: Transmigration of impacted canines: prevalence, management and implications on tooth structure and pulp vitality of adjacent teeth. Clin Oral Investig 2012, 16:625-632.

19. Javid B: Transmigration of impacted mandibular cuspids. Int I Oral Surg 1985, 14:547-549.

20. González-Sánchez MA, Berini-Aytés L, Gay-Escoda C: Transmigrant impacted mandibular canines: a retrospective study of 15 cases. J Am Dent Assoc 2007, 138:1450-1455.

21. Aktan AM, Kara S, Akgünlü F, Malkoç S: The incidence of canine transmigration and tooth impaction in a Turkish subpopulation. Eur $J$ Orthod 2010, 32:575-581.

22. Pedreira EN, Magalhães MC, Cardoso CL, Taveira LA, de Freitas CF: Radiographic study of dental anomalies in Brazilian patients with neuropsychomotor disorders. J Appl Oral Sci 2007, 15:524-528.

23. Peterson LJ: Principles of management of impacted teeth. In Contemporary oral and maxillofacial surgery. Edited by Peterson LJ, Ellis E III, Hupp JR, Tucker MR. St Louis: CV Mosby; 1988:223-256.

24. Bishara SE: Impacted maxillary canines: a review. Am J Orthod Dentofacial Orthop. 1992, 101:159-71.

25. Manne R, Gandikota C, Jurvadi SR, Rama HR, Anche S: Impacted canines: etiology, diagnosis, and orthodontic management. J Pharm Bioallied Sci. 2012, 4:S234-8.

26. Mupparapu M: Patterns of intra-osseous transmigration and ectopic eruption of mandibular canines: review of literature and report of nine additional cases. Dentomaxillofac Radiol 2002, 31:355-360.

27. Celikoglu M, Kamak H, Oktay H: Prevalence and characteristics of supernumerary teeth in a non-syndrome Turkish population: associated pathologies and proposed treatment. Med Oral Patol Oral Cir Bucal 2010, 15:e575-578.

28. Aljamal G, Hazza'a A, Rawashdeh M: Prevalence of dental anomalies in a population of cleft lip and palate patients. Cleft Palate Craniofac J 2010, 47:413-420.

29. Tseng YC, Chang HP, Chou TM: Canine transposition. Kaohsiung J Med Sci 2005, 21:441-447.

30. Shapira Y, Kuftinec MM: Intrabony migration of impacted teeth. Angle Orthod 2003, 73:738-743.

31. Buyukkurt MC, Aras MH, Caglaroglu M, Gungormus M: Transmigrant mandibular canines. J Oral Maxillofac Surg 2007, 65:2025-2029.

32. Joshi MR: Transmigrant mandibular canines: a record of 28 cases and a retrospective review of the literature. Angle Orthod 2001, 71:12-22.

33. Celikoglu M, Kamak H, Oktay H: Investigation of transmigrated and impacted maxillary and mandibular canine teeth in an orthodontic patient population. J Oral Maxillofac Surg 2010, 68:1001-1006.

34. Sumer P, Sumer M, Ozden B, Otan F: Transmigration of mandibular canines: a report of six cases and a review of the literature. J Contemp Dent Pract 2007, 8:104-110

35. Camilleri S, Scerri E: Transmigration of mandibular canines-a review of the literature and a report of five cases. Angle Orthod 2003, 73:753-762

36. Shapira Y, Kuftinec MM: Unusual intraosseous transmigration of a palatally impacted canine. Am J Orthod Dentofacial Orthop 2005, 127:360-363.

37. Gündüz K, Çelenk P: The incidence of impacted transmigrant canines: a retrospective study. Oral Radiol 2010, 26:77-81. 
38. Fardi A, Kondylidou-Sidira A, Bachour Z, Parisis N, Tsirlis A: Incidence of impacted and supernumerary teeth-a radiographic study in a North Greek population. Med Oral Patol Oral Cir Bucal 2011, 16:e56-61.

39. Zvolanek JW: Transmigration of an impacted mandibular canine. Illinois Dental Journal 1986, 55:86-87.

40. Sørensen HB, Artmann L, Larsen HJ, Kjaer I: Radiographic assessment of dental anomalies in patients with ectopic maxillary canines. Int J Paediatr Dent 2009, 19:108-114.

doi:10.1186/1756-0500-7-346

Cite this article as: Kamiloglu and Kelahmet: Prevalence of impacted and transmigrated canine teeth in a Cypriote orthodontic population in the Northern Cyprus area. BMC Research Notes 2014 7:346.

\section{Submit your next manuscript to BioMed Central and take full advantage of:}

- Convenient online submission

- Thorough peer review

- No space constraints or color figure charges

- Immediate publication on acceptance

- Inclusion in PubMed, CAS, Scopus and Google Scholar

- Research which is freely available for redistribution 